\title{
Life cycle indicator comparison of copper, silver, zinc and aluminum nanoparticle production through electric arc evaporation or chemical reduction
}

\author{
Martin Slotte $^{1} \cdot$ Gregory Metha $^{2} \cdot$ Ron Zevenhoven ${ }^{1}$
}

Received: 31 October 2014/ Accepted: 26 March 2015/Published online: 1 May 2015

(c) The Author(s) 2015. This article is published with open access at Springerlink.com

\begin{abstract}
Ways to produce metallic nanoparticles and the scale-up of these processes have seen increased interest as the industrial application of nanoparticles continues to grow. Their feasibility from an environmental point of view can be assessed by means of life cycle analysis (LCA). In this work two methods of metallic nanoparticle production, by evaporation/condensation of metal using electrical arc discharge reactors or by chemical reduction of metal salts in aqueous solutions or dry solid/solid mixtures, are evaluated based on the life cycle indicators. The evaporation of metal using electrical discharge reactors is a method studied in the European Commission 7th Framework Program "BUONAPART-E." The environmental impact of the two different nanoparticle production approaches is here compared for four metals: copper, silver, zinc and aluminum. The chemical routes of producing nanoparticles require several different chemicals and reactions, while the electrical discharge routes use electricity to evaporate metal in a reactor under inert atmosphere. The nanoparticle production processes were modeled using
\end{abstract}

Electronic supplementary material The online version of this article (doi:10.1007/s40095-015-0171-3) contains supplementary material, which is available to authorized users.

Martin Slotte

martin.slotte@abo.fi

Gregory Metha

greg.metha@adelaide.edu.au

Ron Zevenhoven

ron.zevenhoven@abo.fi

1 Thermal and Flow Engineering Laboratory, Åbo Akademi University, Turku, Finland

2 Department of Chemistry, University of Adelaide, Adelaide, South Australia 5005, Australia
"SimaPro" LCA software. Data for both the chemical production routes and the arc routes were taken from the literature. The choice of the best route for the production of each metal is strongly dependent on the final yield of the metallic nanoparticles. The yields for the chemical processes are not reported in the open literature, and therefore the comparisons have to be made with varying yields. At similar yields the electrical process has in general a lower environmental footprint than the studied chemical routes. The step or chemical with the greatest environmental impact varies significantly depending on process and metal being studied.

Keywords LCA - Nanoparticle production - Copper . Silver $\cdot$ Zinc $\cdot$ Aluminum

\section{Introduction}

A way to increase metallic nanoparticle production up to an industrial scale is being studied in the European Commission 7th Framework Program "BUONAPART-E" [1]. The goal is to develop the selected electrical arc discharge evaporation and condensation technique to be able to produce several kilograms of nanoparticles per day [1]. In order to evaluate the environmental impact of the electrical discharge method it needs to be compared with other methods for nanoparticle production. The studied method is a nonchemical route to produce the particles, and chemical synthesis routes were selected for comparison. To compare the environmental effects of the different methods life cycle assessment, LCA, was chosen as a tool. SimaPro 7.3 software using the Ecoinvent v2.2 database is used to calculate the life cycle impact, LCI, of the different nanoparticle production routes using the IMPACT $2002+$ method. In 
this paper the production of nanoparticles of four, copper, silver, zinc and aluminum, out of six metals and two alloys studied in the BUONAPART-E project, is evaluated, with the goal of assessing the environmental impact of the process and to compare the process with chemical synthesis routes for producing the same nanoparticles.

The functional unit is the production of $1 \mathrm{~kg}$ of nanoparticle product. By comparing the LCI for $1 \mathrm{~kg}$ of product for the different synthesis routes, the processes can be evaluated with one common denominator.

The life cycle impact is measured in four categories: human health, ecosystem quality, climate change and resource depletion. All four categories are used to evaluate the processes in order to get a good understanding of the life cycle impact of the nanoparticle production routes. The human health category takes into consideration effects from carcinogens, non-carcinogens, respiratory inorganics, ionizing radiation, ozone layer depletion and respiratory organics emitted as a result of the studied process. Ecosystem quality in turn takes into account aquatic ecotoxicity, terrestrial ecotoxicity, terrestrial acidification and nutrient enrichment and land occupation. The climate change category takes into consideration greenhouse gas emissions, while the resource depletion category the depletion of non-renewable minerals and fossil fuels.

The units used to quantify these categories are: DALY, disability adjusted life years, for human health, PDF $\mathrm{m}^{2}$ year, potentially disappeared fraction multiplied by area and years, for ecosystem quality, kilogram $\mathrm{CO}_{2}$ equivalents, for climate change, and MJ primary energy for the resource depletion category. DALY is a measure of overall disease burden which is expressed as years lost due to illhealth, disability or death. PDF is a measure given for species affected by toxins at certain concentrations. $\mathrm{CO}_{2}$ equivalents are defined as the amount of $\mathrm{CO}_{2}$ that would have the same global warming effect for a given gas mixture. The gas mixture considered in this study consists of carbon dioxide, carbon monoxide, chloroform, nitrogen dioxide, ethane, methane and sulfur hexafluoride. The MJ primary energy needed is the energy needed to extract the same minerals in the future as were used presently.

Another unit is also used; this unit is LCI points ( $\mathrm{Pt}$ ). This unit is used to compare the environmental impact of a process to the emissions caused by one average European citizen per year; $1000 \mathrm{Pt}$ is equal to one citizen.

\section{Evaporation/condensation of metal using electric discharge}

The electrical arc method to produce pure metallic nanoparticles consists of evaporating a pure metal with the energy delivered with the electrical discharge. The metal is under an inert atmosphere at atmospheric or a slight underpressure. Different setups are being studied by a few project partners but in general the discharge is established between two metallic electrodes at a certain distance from each other. The size distribution, morphology, composition and yield of the aerosol particles are dependent on the electrode material, carrier gas composition and the type and energy input of the electrical discharge [2].

The metal to be evaporated is fed into the reactor and functions as the anode. A tungsten rod is used as the cathode which is connected to the power supply. The carrier gas is fed into the reactor and transports the evaporated metal out of the reactor. Once outside the electrical discharge region, the metal vapor nucleates and forms nanosized particles. The particles are collected on a filter, and the carrier gas, now called exhaust gas, exits the system. A scheme of the process can be seen in Fig. 1. Not all of the product gets carried out of the reactor by the carrier gas. Some vapor remains in the reactor to nucleate and form particles on the cooled inner walls of the reactor. These particles have different size distribution and morphology [3] and will not show up in the filter and will not exit the system as a product. The useless product particles can be recycled and reshaped into new electrodes. Such recycling of these particles is not taken into consideration in this study. Also, recovery of exhaust gas and reuse as carrier gas are not yet considered.

The study takes into account the impact of the mining, refining of the metals, production of carrier gas through separation from air and the transport of both gas and metals to the nanoparticle production plant. The generation of electricity used to evaporate the metals in the nanoparticle production process is also taken into account. Figure 2 shows the system boundary for the arc process studied. The impact caused by infrastructure is not considered.

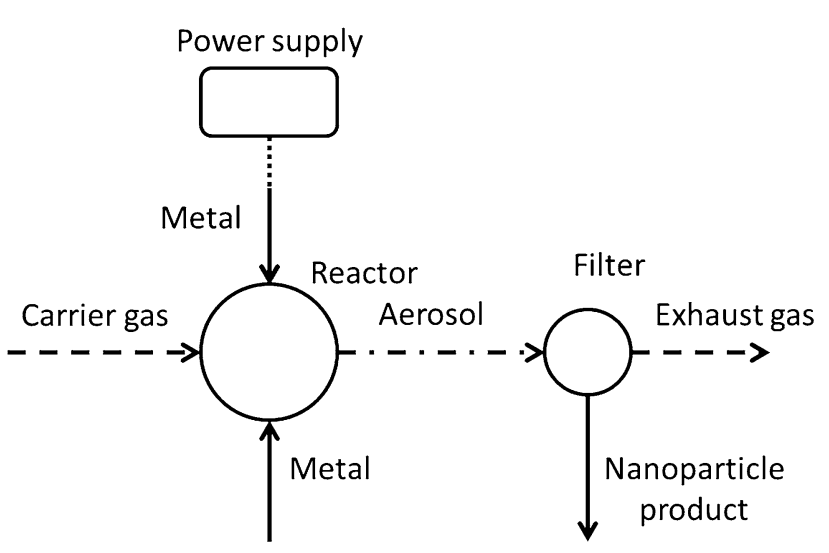

Fig. 1 Scheme for electric arc/spark reactor setup 


\section{Evaporation of copper using arc discharge}

An ultrapure copper wire is connected as the anode and is evaporated by electric discharges. Pure nitrogen gas is used as carrier gas. The process is modeled starting from copper at a primary copper-producing plant, nitrogen gas produced through cryogenic air separation and electricity produced in Germany with an average mix of power production technologies. The copper is shipped (assumed here by container ship) to the nanoparticle production plant where it is first vacuum-melted in order to purify it to the required purity before being shaped to the wire used as the anode. The nitrogen gas is produced close to the nanoparticle production plant and shipped in gas bottles by trucks. The electricity used is assumed to be the consumer mix of Germany. The LCI network used for the calculations, showing the various inputs, can be seen in Appendix A.

\section{Evaporation of silver using arc discharge}

Silver nanoparticles are produced in the same way with the same process as copper particles. Metallic silver is shipper to the nanoparticle production plant by ship, and the nitrogen is shipped by truck in gas bottles. Similar to that for copper nanoparticle production, the LCI network can be seen in Appendix B.

\section{Evaporation of zinc using arc discharge}

The evaporation technique for nanoparticle zinc is similar to that for both copper and silver with the exception that the use of argon gas gives better results. The process is modeled in a similar way with the exception of using argon as the carrier gas. Appendix C shows the LCI network used for calculating the impact of producing nanoparticle zinc using the arc process.

\section{Evaporation of aluminum using arc discharge}

A same technique is used to produce nanoparticle aluminum as for copper except with the use of argon as the carrier gas as for zinc nanoparticle production. The material yield of aluminum nanoparticles is significantly lower than for the other three metals.

\section{Reference chemical methods for nanoparticle production}

This study takes into account the production of the reagents and the transport of these to the nanoparticle production facility as well as the energy needed to produce the nanoparticles. The LCIs of the particles after production are not considered. The final yields of nanoparticle product were poorly reported, and similar yields as for the arc process were assumed. There are no standard chemical ways for producing metallic nanoparticles. The required size and shape, as well as what metal is being used, determine the synthesis route. For this study chemical reduction of metal containing precursor is selected as synthesis route. The routes are similar for the synthesis of both copper and silver, with the same reducing agent being used in a wet chemical route. The synthesis of zinc nanoparticles is significantly different from the routes for copper and silver nanoparticles: Among other things it requires the use of another reducing agent. The synthesis route to produce aluminum nanoparticles is completely different from those for the other three metals. A dry solid/solid synthesis route in an inert atmosphere was studied. The reducing agent is also different from the synthesis routes of the three other metals. Only nanoparticle production methods, with sufficient data on the synthesis route published and using chemicals or precursors available in the Ecoinvent 2.2 database or that can be modeled with the base chemicals available in said database, were used.
Fig. 2 Schematic representation of the system boundary

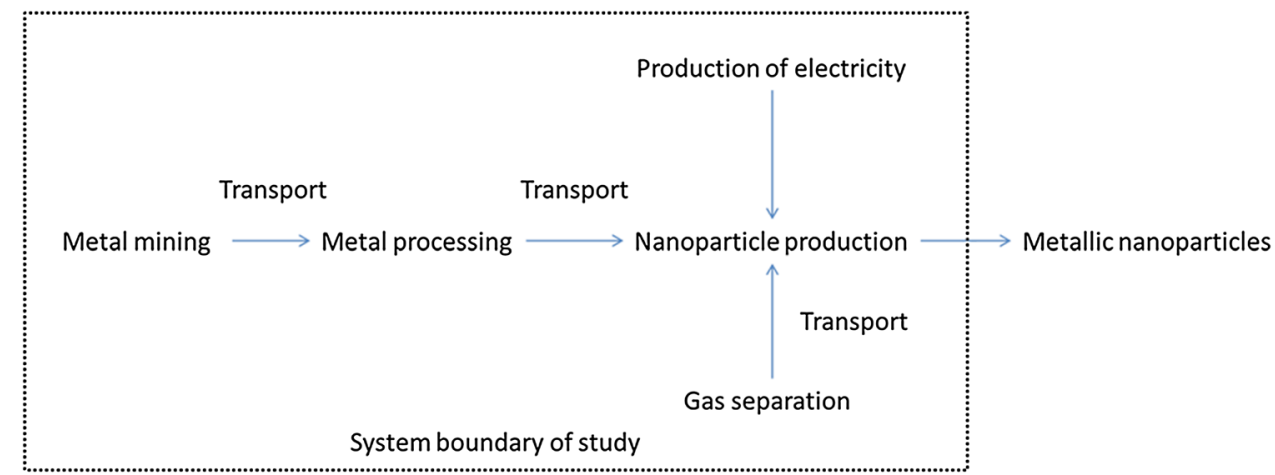




\section{Synthesis of copper nanoparticles}

The chemical way of producing copper nanoparticles studied in this work is the one presented by Lisiecki et al. [6], where copper dodecyl sulfate $\left(\mathrm{Cu}(\mathrm{DS})_{2}\right)$ is reduced with sodium borohydride, $\mathrm{NaBH}_{4}$, in aqueous solution.

The LCI for neither $\mathrm{Cu}(\mathrm{DS})_{2} \mathrm{Cu}\left(\mathrm{C}_{12} \mathrm{H}_{2 \mathrm{~s}} \mathrm{SO}_{4}\right)_{2}$ or $\mathrm{NaBH}_{4}$ was available in the SimaPro database and therefore had to be modeled. The process for producing nanoparticle copper through chemical reduction of copper precursor was modeled as follows:

The synthesis of sodium borohydride is a multi-step process [7]. The metallic sodium is mainly produced from molten sodium chloride by electrowinning (Downs' process). The salt is mixed with calcium chloride, molar ratio $1: 3$, to reduce the melting point, from $804{ }^{\circ} \mathrm{C}$ for pure $\mathrm{NaCl}$ to $\sim 600{ }^{\circ} \mathrm{C}$ for the mixture. An electric current is fed through the molten salts, usually at $7-8$ volts and 25-40 kA. The electric current breaks the salt into pure sodium and chloride gas:

$\mathrm{NaCl} \rightarrow \mathrm{Na}+\frac{1}{2} \mathrm{Cl}_{2}$.

The produced metallic sodium is reacted with hydrogen gas in order to produce sodium hydride:

$\mathrm{Na}+\frac{1}{2} \mathrm{H}_{2} \rightarrow \mathrm{NaH}$.

Trimetylborate, $\mathrm{B}\left(\mathrm{OCH}_{3}\right)_{3}$, another precursor in the production of sodium borohydride is produced by reacting boric acid with methanol:

$\mathrm{H}_{3} \mathrm{BO}_{3}+3 \mathrm{CH}_{3} \mathrm{OH} \rightarrow \mathrm{B}\left(\mathrm{OCH}_{3}\right)_{3}+3 \mathrm{H}_{2} \mathrm{O}$.

Finally the $\mathrm{NaBH}_{4}$ is produced

$4 \mathrm{NaH}+\mathrm{B}\left(\mathrm{OCH}_{3}\right)_{3} \rightarrow \mathrm{NaBH}_{4}+3 \mathrm{NaOCH}_{3}$.

Like the production of sodium borohydride, the production of copper dodecyl sulfate is also a multi-step process. The process starts with the production of copper sulfate solution, which is one of the precursors for copper dodecyl sulfate, from metallic copper using sulfuric acid.

$\mathrm{Cu}+\mathrm{H}_{2} \mathrm{SO}_{4} \rightarrow \mathrm{CuSO}_{4}+\mathrm{H}_{2}$.

During copper production metallic copper is typically produced from a copper sulfate solution through electrowinning. The step of producing copper sulfate could be avoided if copper sulfate solution from the upstream step of copper production is used.

Hydrogen lauryl sulfate is the next precursor needed for the process in which lauryl alcohol is reacted with sulfuric acid forming hydrogen lauryl sulfate and water

$$
\mathrm{C}_{12} \mathrm{H}_{25} \mathrm{OH}+\mathrm{H}_{2} \mathrm{SO}_{4} \rightarrow \mathrm{C}_{12} \mathrm{H}_{25} \mathrm{HSO}_{4}+\mathrm{H}_{2} \mathrm{O} \text {. }
$$

Sodium lauryl sulfate is synthesized from hydrogen lauryl sulfate and sodium carbonate

$2 \mathrm{C}_{12} \mathrm{H}_{25} \mathrm{HSO}_{4}+\mathrm{Na}_{2} \mathrm{CO}_{3} \rightarrow 2 \mathrm{NaC}_{12} \mathrm{H}_{25} \mathrm{SO}_{4}+\mathrm{H}_{2} \mathrm{CO}_{3}$.

Sodium lauryl sulfate is reacted with copper sulfate to form copper lauryl sulfate and sodium sulfate

$2 \mathrm{NaC}_{12} \mathrm{H}_{25} \mathrm{SO}_{4}+\mathrm{CuSO}_{4} \rightarrow \mathrm{Cu}\left(\mathrm{C}_{12} \mathrm{H}_{25} \mathrm{SO}_{4}\right)_{2}+\mathrm{NaSO}_{4}$.

The final step in the synthesis is to react the copper lauryl sulfate with sodium borohydride, forming copper nanoparticles together with some by-products

$\mathrm{Cu}\left(\mathrm{C}_{12} \mathrm{H}_{25} \mathrm{SO}_{4}\right)_{2}+\mathrm{NABH}_{4} \rightarrow \mathrm{Cu}+$ by-products.

The LCI network for the chemical route for producing nanoparticle copper can be seen in the Appendix D.

\section{Synthesis of silver nanoparticles}

The synthesis route for nanoparticle silver studied is the one described by Lee et al. [8]. In this process a silver nitrate solution is reduced to metallic silver using a sodium borohydride solution. Separation of the formed metallic nanoparticles from the solution is not considered in this study.

The LCI for silver nitrate solution is not available in the SimaPro database. The synthesis of silver nitrate is therefore modeled from the reaction of metallic silver with $50 \%$ aqueous nitric acid solution. The formed silver nitrate is then diluted to the right concentration using ultrapure water. The silver nitrate is produced according to (10)

$\mathrm{Ag}+2 \mathrm{HNO}_{3} \rightarrow \mathrm{AgNO}_{3}+\mathrm{H}_{2} \mathrm{O}+\mathrm{NO}_{2}$

$\mathrm{AgNO}_{3}+\mathrm{NaBH}_{4} \rightarrow \mathrm{Ag}+\mathrm{BH}_{3}+\mathrm{HNO}_{3}+\mathrm{NaNO}_{3}$.

Sodium borohydride is prepared in the same way as in the process to produce copper nanoparticles (see "Synthesis of copper nanoparticles"). The LCI network for the chemical route for producing nanoparticle silver can be seen in the Appendix E.

\section{Synthesis of zinc nanoparticles}

The process for synthesizing metallic zinc nanoparticles is described by Ghanta et al. [9]. The final reaction in the process is the reaction of zinc chloride with lithium borohydride [9].

$$
\begin{aligned}
\mathrm{ZnCl}_{2} & +2 \mathrm{LiBH}_{4} \stackrel{\text { Mesitylene }}{\longrightarrow} \mathrm{Zn}+\mathrm{BH}_{3}+\left(\mathrm{B}_{12} \mathrm{H}_{12}\right)^{2-}+\mathrm{LiCl} \\
& + \text { other by-products. }
\end{aligned}
$$


Neither of the precursors needed for the synthesis can be found in the SimaPro 7 database and therefore need to be modeled. The synthesis process is modeled according to the chemical reaction steps. Metallic zinc is reacted with hydrochloric acid to form zinc chloride.

$\mathrm{Zn}+2 \mathrm{HCl} \rightarrow \mathrm{ZnCl}_{2}+\mathrm{H}_{2}$.

Sodium borohydride is synthesized as described above (see "Synthesis of copper nanoparticles").

Bromine gas is produced by the steaming-out process in which chlorine gas is used as an oxidant [10].

The bromine gas is hydrated, forming hydrogen bromide:

$\frac{1}{2} \mathrm{H}_{2}+\frac{1}{2} \mathrm{Br}_{2} \rightarrow \mathrm{HBr}$.

Lithium bromide is made from the reaction of lithium hydroxide and hydrogen bromide.

$\mathrm{LiOH}+\mathrm{HBr} \rightarrow \mathrm{LiBr}+\mathrm{H}_{2} \mathrm{O}$.

Lithium borohydride is formed in the reaction of sodium borohydride with lithium bromide

$\mathrm{NaBH}_{4}+\mathrm{LiBr} \rightarrow \mathrm{NABr}+\mathrm{LiBH}_{4}$

The LCI network for the chemical route for producing nanoparticle zinc can be seen in the Appendix F.

\section{Synthesis of aluminum nanoparticles}

The process for producing aluminum nanoparticles is, unlike for the other three metals, not a wet aqueous process. The method selected for this study is a mechanochemical process described by Paskevicius et al. [11]. The process works by ball milling a mixture of aluminum chloride and lithium in an inert atmosphere, in this case nitrogen. Small amounts of lithium chloride are added to the mix in order to prevent combustion. A ball to powder mass ratio of 35:1 was used. During the milling the $\mathrm{AlCl}_{3}$ is reduced by the lithium according to reaction (17).

$\mathrm{AlCl}_{3}+\mathrm{Li} \rightarrow \mathrm{Al}+3 \mathrm{LiCl}$.

$\mathrm{AlCl}_{3}$ is not available in the Ecoinvent 2.2 database and had to be modeled. It was modeled as a reaction between chlorine gas and solid aluminum.

The newly formed $\mathrm{Al}$ particles are embedded in larger $\mathrm{LiCl}$ particles. Nitromethane is used dissolve the $\mathrm{LiCl}$ without oxidizing the aluminum. After washing the wet $\mathrm{Al}$ particles are left to dry.

The LCI network for the mechanochemical route for producing nanoparticle aluminum can be seen in the Appendix G.

\section{Results and discussion}

\section{Nanoparticulate copper}

The absolute values for the different impact categories are not the main focus in this study; emphasis is placed on the comparison of the different methods.

Due to the low product yield (=the efficiency of product material leaving the system via the filter), around $20 \%$, obtained by the BUONAPART-E project partners so far, the environmental footprint is significantly higher than what it would be for a $100 \%$ yield. This is due to the fact that only a small fraction of the produced particles is collected on the filter, while most of the evaporated material can be found as particles in the reactor chamber (Table 1).

As can be seen in Table 2 the biggest impact on human health and ecosystem quality comes from the pure copper used for the process, while the electricity used is the main cause of climate change and resource depletion. Table 2 shows the footprint for $1 \mathrm{~kg}$ of copper nanoparticle product. Even though the nitrogen gas has the lowest impact on LCI it can still be reduced by recycling the gas once it passes through the particle filter.

By improving the flow patterns in the reactor and thereby raising the amount of particles that reach the filter, the footprint of the particle production can be reduced significantly. Table 2 also shows the LCI for the copper nanoparticle in case the material was obtained at $100 \%$ material efficiency. The proportions between the different sources remain the same but are directly proportional to the increased yield.

As can be seen in Table 3, for a salt reduction production route, the production of the copper precursor is the main cause of human health and ecosystem quality impacts, while it is the production of the reducing agent which is the main cause of the climate change and resource depletion impacts. During the production of sodium borohydride it is the production of the metallic sodium which is the least environmentally friendly step.

Figure 3 shows the comparison of the human health, ecosystem quality, climate change and resource categories for copper nanoparticle production through arc discharge evaporation and the chemical reduction method. The LCI are calculated for $100 \%$ material efficiency, theoretical max yield (i.e., all of the metal fed into the process comes out as product nanoparticles without material losses). Figure 3 also shows the LCI for the arc discharge process at currently achieved experimental yields. As can be seen the overall impact of the arc discharge evaporation method has is lower than for the chemical reduction method. It is only in the ecosystem quality category where the impact of the evaporation and chemical route are similar; in the other 
Table 1 Nanoparticle production rate and power consumption for $\mathrm{Cu}, \mathrm{Ag}$ and $\mathrm{Zn} \mathrm{[4]} \mathrm{and} \mathrm{Al}[5]$

\begin{tabular}{llllll}
\hline Material & Gas & $\begin{array}{l}\text { Power } \\
(\mathrm{kW})\end{array}$ & $\begin{array}{l}\text { Electrode } \\
\text { mass loss } \\
\text { rate }(\mathrm{g} / \mathrm{h})\end{array}$ & $\begin{array}{l}\text { Filter } \\
\text { collection } \\
\text { rate }(\mathrm{g} / \mathrm{h})\end{array}$ & $\begin{array}{l}\text { Experimental } \\
\text { material yield } \\
(\%)\end{array}$ \\
\hline $\mathrm{Cu}$ & $\mathrm{N}_{2}$ & 1.88 & 71.0 & 13.5 & 19.0 \\
$\mathrm{Ag}$ & $\mathrm{N}_{2}$ & 1.60 & 13.9 & 2.6 & 18.7 \\
$\mathrm{Zn}$ & $\mathrm{Ar}$ & 0.40 & 27.8 & 5.3 & 19.1 \\
$\mathrm{Al}$ & $\mathrm{Ar}$ & 0.80 & 0.032 & 0.001 & 3.5 \\
\hline
\end{tabular}

Table 2 LCI for arc method of producing copper nanoparticles

\begin{tabular}{|c|c|c|c|c|}
\hline & & $\begin{array}{l}\text { Nitrogen } \\
\text { gas }\end{array}$ & $\begin{array}{l}\text { Pure } \\
\text { copper }\end{array}$ & Electricity \\
\hline \multicolumn{5}{|l|}{$20 \%$ Yield } \\
\hline Human health & DALY & 0.00001 & 0.00032 & 0.00002 \\
\hline $\begin{array}{l}\text { Ecosystem } \\
\text { quality }\end{array}$ & PAF $\mathrm{m}^{2}$ year & 0.26 & 212.43 & 1.00 \\
\hline Climate change & $\mathrm{kg} \mathrm{CO} \mathrm{CO}_{2}$ & 10.31 & 26.12 & 95.46 \\
\hline $\begin{array}{l}\text { Resource } \\
\text { depletion }\end{array}$ & MJ Primary & 196.33 & 490.04 & 1539.40 \\
\hline \multicolumn{5}{|l|}{$100 \%$ Yield } \\
\hline Human health & DALY & 0.000001 & 0.000061 & 0.000003 \\
\hline $\begin{array}{l}\text { Ecosystem } \\
\text { quality }\end{array}$ & PAF $\mathrm{m}^{2}$ year & 0.05 & 40.39 & 0.19 \\
\hline Climate change & $\mathrm{kg} \mathrm{CO} \mathrm{CO}_{2}$ eq & 1.96 & 4.97 & 18.15 \\
\hline $\begin{array}{l}\text { Resource } \\
\text { depletion }\end{array}$ & MJ Primary & 37.33 & 93.18 & 292.70 \\
\hline
\end{tabular}

Table 3 LCI for chemical reduction method of producing copper nanoparticles at $100 \%$ yield

\begin{tabular}{llll}
\hline & & $\begin{array}{l}\text { Copper } \\
\text { precursor }\end{array}$ & $\begin{array}{l}\text { Reducing } \\
\text { agent }\end{array}$ \\
\hline Human health & DALY & 0.00009 & 0.00004 \\
Ecosystem quality & $\mathrm{PAF} \mathrm{m}^{2}$ year & 36.92 & 11.93 \\
Climate change & $\mathrm{kg} \mathrm{CO}_{2}$ eq & 20.45 & 64.78 \\
Resource depletion & MJ Primary & 266.34 & 997.42 \\
\hline
\end{tabular}

categories the impact is significantly lower for the discharge method.

\section{Nanoparticulate silver}

The metallic silver is evaporated in a pure nitrogen atmosphere using electric discharges. As is the case for the copper nanoparticle production the majority of the evaporated silver stays in the reactor and does not exit the system as product. The yield of silver is similar to that for copper at $18.7 \%$. Table 4 shows the LCI for the carrier gas, silver and the electricity used to produce the nanoparticles. The nitrogen gas production and transport have the highest impacts on human health and ecosystem quality, while the biggest impact on climate change and resource depletion comes from the production of the electricity needed.

The life cycle impacts of the two different methods of producing silver nanoparticles are very similar. For the human health, ecosystem quality and climate change the impact from the dry production method is smaller, while for the resource depletion it is greater.

Table 5 shows the LCI for silver nanoparticle production through chemical reduction of silver nitrate. The production of the silver precursor has a higher LCI than the reducing agent in both human health and ecosystem quality categories. For climate change and resource depletion categories the reducing agent has a larger LCI.

Figure 4 shows the LCI for both the arc discharge process and chemical process for $100 \%$ material yield and the currently achieved experimental yield. As can be seen, at equal material yields, in all categories except resource depletion, the arc process is superior to the studied chemical route to produce nanoparticle silver.

\section{Nanoparticulate zinc}

As can be seen in Table 6 the argon carrier gas plays a significant part in the LCI of the process of producing zinc nanoparticles by arc discharge evaporation. The resource depletion and climate change effect caused by the argon gas are a magnitude larger than those of the zinc. The electricity production causes the biggest LCI in both climate change and resource depletion, while the zinc production from ore stands for the highest LCI on the ecosystem quality.

The main LCI in the chemical reduction route for producing nanoparticle zinc is the synthesis of the $\mathrm{LiBH}_{4}$ used as the reducing agent. The LCI for each category is presented in Table 7 for both the zinc precursor and the reducing agent. In three out of four categories the impact of the production of the reducing agent is more than one magnitude greater than for the production of the zinc precursor.

As can be seen in Fig. 5 the LCI in all four categories is lower for the electrical discharge method compared with that of the chemical reduction method. The LCI for zinc nanoparticles produced by the electrical discharge method is less than half compared with the chemical reduction method in both the human health and ecosystem quality categories. In the other categories the difference between the two methods is not as significant. 


\section{Human health}

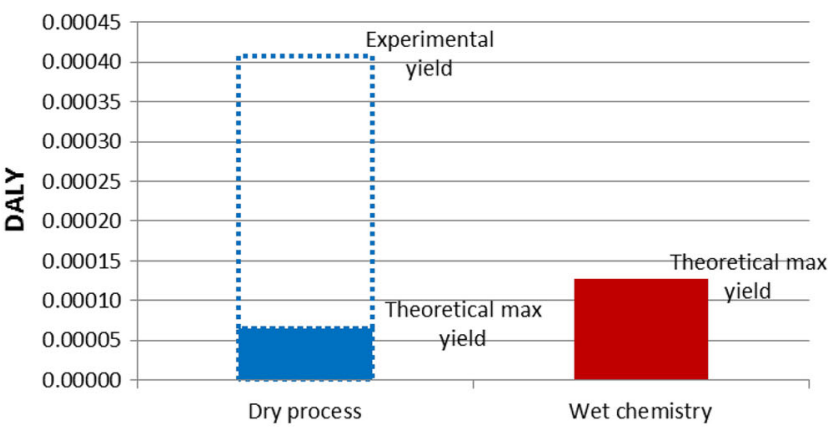

Climate change

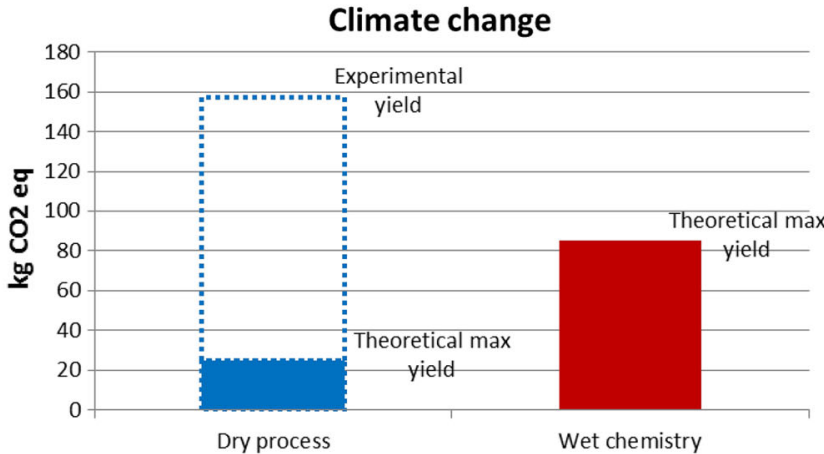

Ecosystem quality

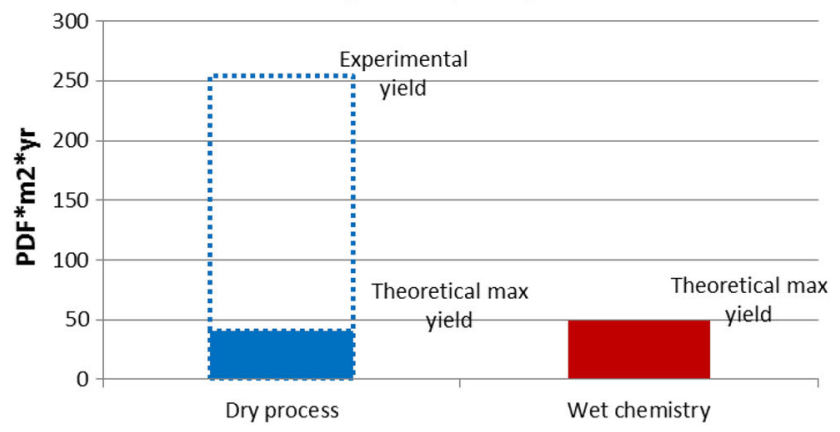

Resources

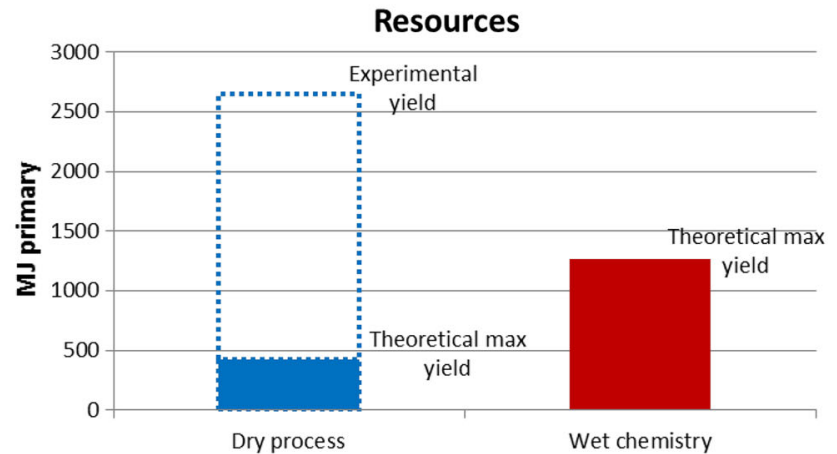

Fig. 3 LCI comparison for evaporation method and chemical reduction method for copper particles

Table 4 LCI for arc method of producing silver nanoparticles

\begin{tabular}{|c|c|c|c|c|}
\hline & & $\begin{array}{l}\text { Nitrogen } \\
\text { gas }\end{array}$ & $\begin{array}{l}\text { Pure } \\
\text { silver }\end{array}$ & Electricity \\
\hline \multicolumn{5}{|l|}{$19 \%$ Yield } \\
\hline Human health & DALY & 0.00246 & 0.00014 & 0.00007 \\
\hline $\begin{array}{l}\text { Ecosystem } \\
\text { quality }\end{array}$ & PAF $\mathrm{m}^{2}$ year & 474.43 & 24.56 & 4.42 \\
\hline Climate change & $\mathrm{kg} \mathrm{CO}_{2}$ eq & 287.56 & 244.18 & 421.85 \\
\hline $\begin{array}{l}\text { Resource } \\
\text { depletion }\end{array}$ & MJ Primary & 3547.88 & 5079.22 & 6802.57 \\
\hline \multicolumn{5}{|l|}{$100 \%$ Yield } \\
\hline Human health & DALY & 0.00046 & 0.00003 & 0.00001 \\
\hline $\begin{array}{l}\text { Ecosystem } \\
\text { quality }\end{array}$ & PAF $\mathrm{m}^{2}$ year & 88.74 & 4.59 & 0.83 \\
\hline Climate change & $\mathrm{kg} \mathrm{CO}_{2}$ eq & 53.79 & 45.67 & 78.91 \\
\hline $\begin{array}{l}\text { Resource } \\
\text { depletion }\end{array}$ & MJ Primary & 663.63 & 950.07 & 1272.42 \\
\hline
\end{tabular}

\section{Nanoparticulate aluminum}

The LCI results for the arc process for producing nanoparticle aluminum are shown in Table 8 . Due to the very low material yield in the experiments the LCI for aluminum is very high compared with what it could be if all of the evaporated metal would be captured as product.
Table 5 LCI for chemical reduction method of producing silver nanoparticles at $100 \%$ yield

\begin{tabular}{llll}
\hline & & $\begin{array}{l}\text { Silver } \\
\text { precursor }\end{array}$ & $\begin{array}{l}\text { Reducing } \\
\text { agent }\end{array}$ \\
\hline Human health & DALY & 0.00047 & 0.00008 \\
Ecosystem quality & $\mathrm{PAF} \mathrm{m}^{2}$ year & 92.04 & 29.80 \\
Climate change & $\mathrm{kg} \mathrm{CO}_{2}$ eq & 64.51 & 132.86 \\
Resource depletion & MJ Primary & 798.76 & 2072.74 \\
\hline
\end{tabular}

The use of argon gas as carrier gas gives rise to the largest impact on the environment in all LCI categories, while the electricity gives rise to the second biggest impact.

For the mechanochemical process for producing nanoparticulate aluminum the main contributor to the environmental impact is the nitromethane used to wash the particles after synthesis. It contributes to $70-80 \%$ of the emissions in all four LCI categories. By using another more environmentally friendly washing agent or by recycling it the LCI of the process could be reduced drastically.

As can be seen in Fig. 6 the mechanochemical route has lower LCI than the arc discharge method in all four categories. The emissions from the arc discharge process are several times larger than those for the mechanochemical process, 9, 811 and 13 for human health, ecosystem quality, climate change and resources, respectively. 
Human health
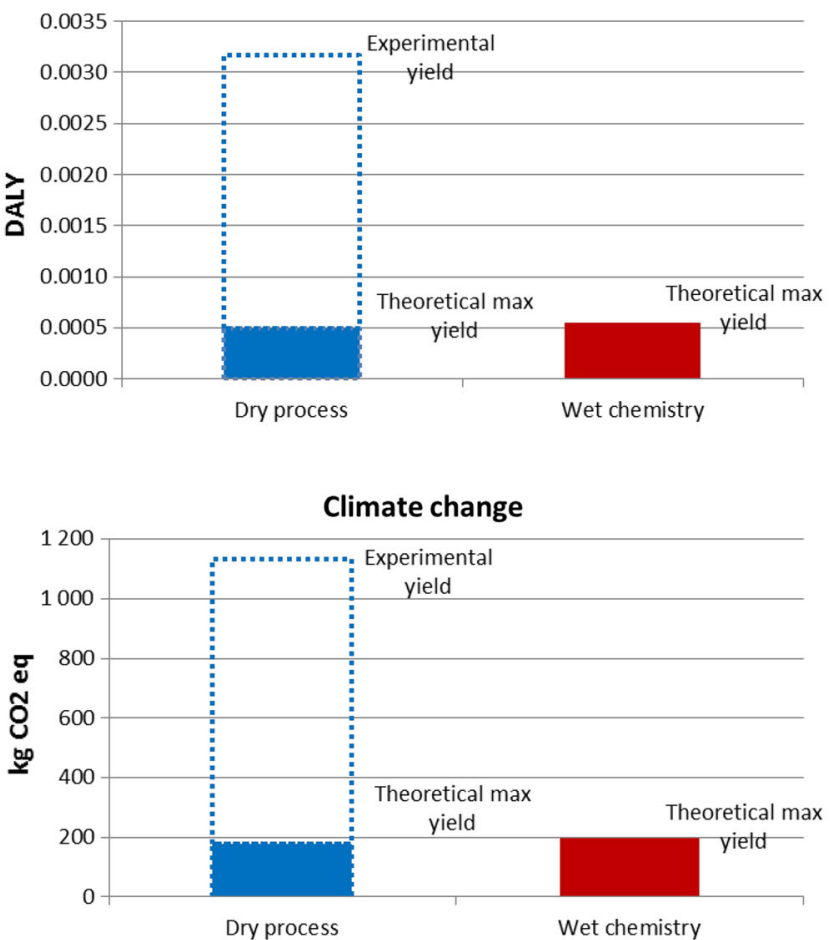

\section{Ecosystem quality}
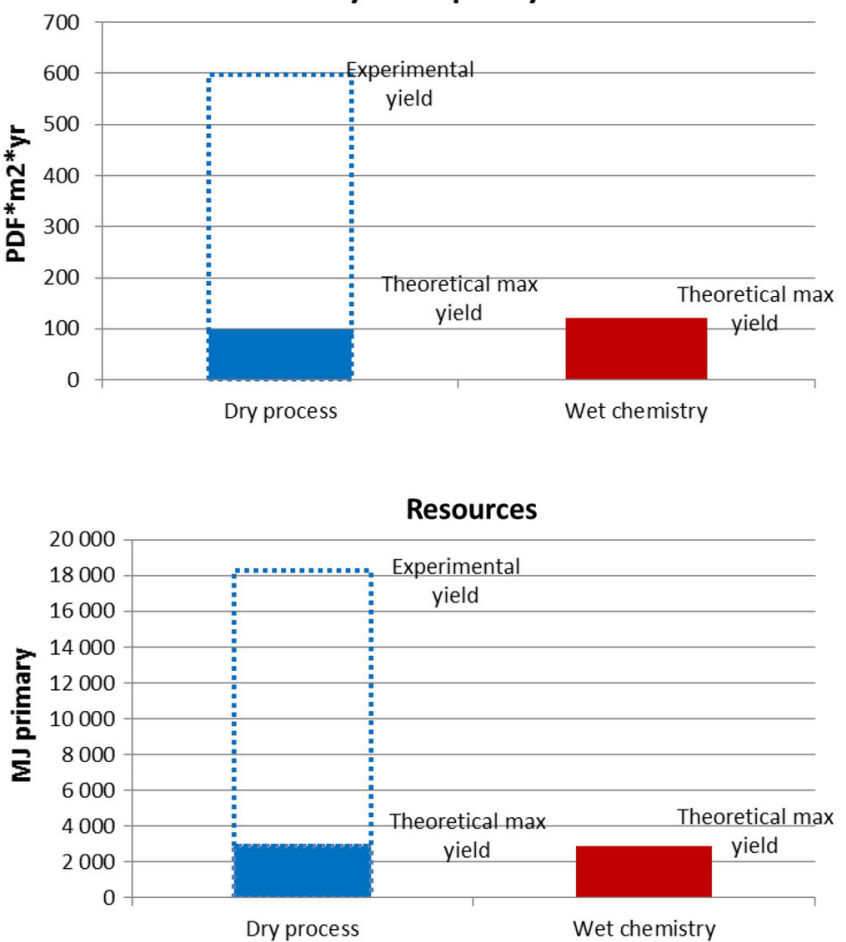

Fig. 4 LCI comparison for evaporation method and chemical reduction method for silver particles

Table 6 LCI for arc method of producing zinc nanoparticles

\begin{tabular}{|c|c|c|c|c|}
\hline & & $\begin{array}{l}\text { Argon } \\
\text { gas }\end{array}$ & Pure zinc & Electricity \\
\hline \multicolumn{5}{|l|}{$20 \%$ Yield } \\
\hline Human health & DALY & 0.000071 & 0.000024 & 0.000035 \\
\hline $\begin{array}{l}\text { Ecosystem } \\
\text { quality }\end{array}$ & PAF $\mathrm{m}^{2}$ year & 12.39 & 19.82 & 2.17 \\
\hline Climate change & $\mathrm{kg} \mathrm{CO}_{2}$ eq & 139.40 & 17.28 & 206.94 \\
\hline $\begin{array}{l}\text { Resource } \\
\text { depletion }\end{array}$ & MJ Primary & 2891.08 & 151.26 & 3337.11 \\
\hline \multicolumn{5}{|l|}{$100 \%$ Yield } \\
\hline Human health & DALY & 0.000014 & 0.000005 & 0.000007 \\
\hline $\begin{array}{c}\text { Ecosystem } \\
\text { quality }\end{array}$ & PAF $\mathrm{m}^{2}$ year & 2.36 & 3.78 & 0.41 \\
\hline Climate change & $\mathrm{kg} \mathrm{CO}_{2}$ eq & 26.58 & 3.29 & 39.45 \\
\hline $\begin{array}{l}\text { Resource } \\
\text { depletion }\end{array}$ & MJ Primary & 551.18 & 28.84 & 636.21 \\
\hline
\end{tabular}

When comparing the LCI results presented above the electrical discharge evaporation of copper (Fig. 3) has a significantly lower impact on the environment compared with the chemical route. For the production of silver nanoparticles the environmental impact is very similar for both the physical and chemical routes (Fig. 4), while for zinc the electric discharge evaporation route is significantly better in all but one category (Fig. 5). For aluminum the
Table 7 LCI for chemical reduction method of producing zinc nanoparticles at $100 \%$ yield

\begin{tabular}{llll}
\hline & & $\begin{array}{l}\text { Zinc } \\
\text { precursor }\end{array}$ & $\begin{array}{l}\text { Reducing } \\
\text { agent }\end{array}$ \\
\hline Human health & DALY & 0.000004 & 0.000049 \\
Ecosystem quality & $\mathrm{PAF} \mathrm{m}^{2}$ year & 3.89 & 12.62 \\
Climate change & $\mathrm{kg} \mathrm{CO}_{2}$ eq & 3.53 & 94.47 \\
Resource depletion & MJ Primary & 33.87 & 1370.52 \\
\hline
\end{tabular}

LCI is lower for all categories for the mechanochemical process. The chemical routes all require pure metals as a starting point for the synthesis as well as other chemicals. The production of these chemicals is energy and resource intensive resulting in high LCI's. This is the case as long as the yields of the chemical routes and the arc route are similar. Even though more chemicals are used in the mechanochemical process it still has a significantly lower environmental impact at comparable yields (Table 9).

The final size of the nanoparticles varies according to the method used in the synthesis. The functionality of the produced particles is likely to be different depending on the synthesis route used. In order to achieve the required shape, size and size distribution the particles will most likely require further processing (sieving, agglomeration etc.). The average particle size for each metal and method is 

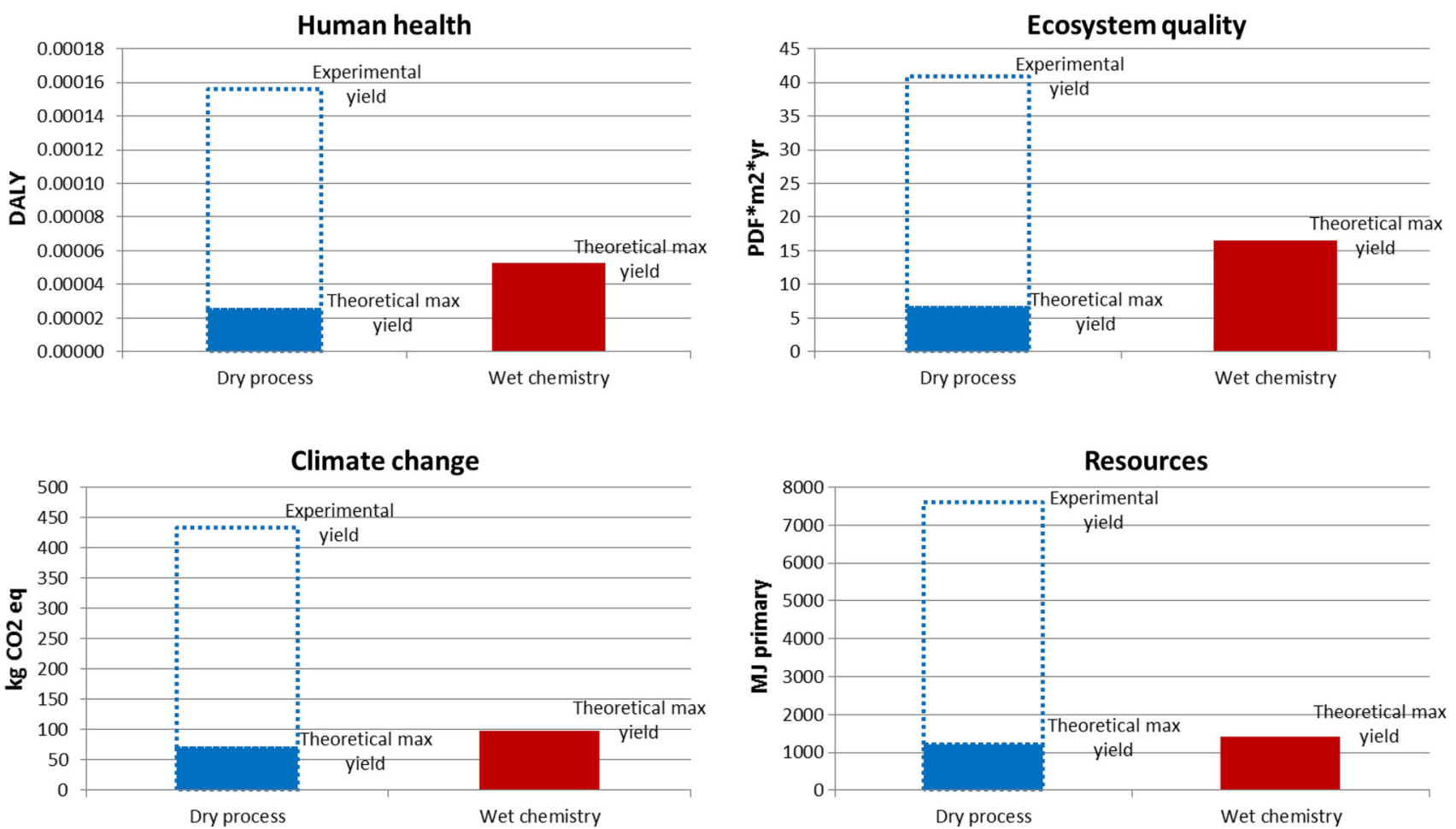

Fig. 5 LCI comparison for evaporation method and chemical reduction method for zinc particles

Table 8 LCI for arc method of producing aluminum nanoparticles

\begin{tabular}{|c|c|c|c|c|}
\hline & & Argon gas & Pure aluminum & Electricity \\
\hline \multicolumn{5}{|c|}{$3.5 \%$ Yield (Experimental yield) } \\
\hline Human health & DALY & 0.36127 & 0.00035 & 0.09405 \\
\hline Ecosystem quality & PAF $\mathrm{m}^{2}$ year & 64,754 & 79 & 5749 \\
\hline Climate change & $\mathrm{kg} \mathrm{CO} \mathrm{CO}_{2}$ & 653,247 & 411 & 548,402 \\
\hline Resource depletion & MJ Primary & $13,943,147$ & 5300 & $8,843,341$ \\
\hline \multicolumn{5}{|c|}{$100 \%$ Yield (Theoretical max yield) } \\
\hline Human health & DALY & 0.01129 & 0.00001 & 0.00294 \\
\hline Ecosystem quality & PAF $\mathrm{m}^{2}$ year & 2024 & 2 & 180 \\
\hline Climate change & $\mathrm{kg} \mathrm{CO} \mathrm{CO}_{2}$ eq & 20,414 & 13 & 17,138 \\
\hline Resource depletion & MJ Primary & 435,723 & 166 & 276,354 \\
\hline
\end{tabular}

presented in Table 10. Since the particle size can be tuned by varying the parameters for the chemical synthesis routes, comparing the final functionality of the particles is difficult. As can be seen in Table 10 the particle size for the arc process is in general in the same scale as for the chemical route.

\section{Effect of location of electricity production}

How electricity is generated varies as different mixes of generation technologies are used in different countries. The LCI calculations in this study are done with the electricity generation technology mix in Germany. In order to validate the applicability of the study the LCI for the arc process was also calculated with the electricity mix for other countries than Germany. This was done for the EU-27, Norwegian, Spanish and USA electricity mixes. The results are presented in Table 11. As can be seen the difference in the emissions between countries varies very little. The only country mix that shows a significant difference is the Norwegian mix. This is most likely due to the high share of hydropower used in Norway.

The LCI of the arc discharge method is dependent on the final material yield. The difference in LCI between producers can be seen in Appendix H. Part of the experiments 

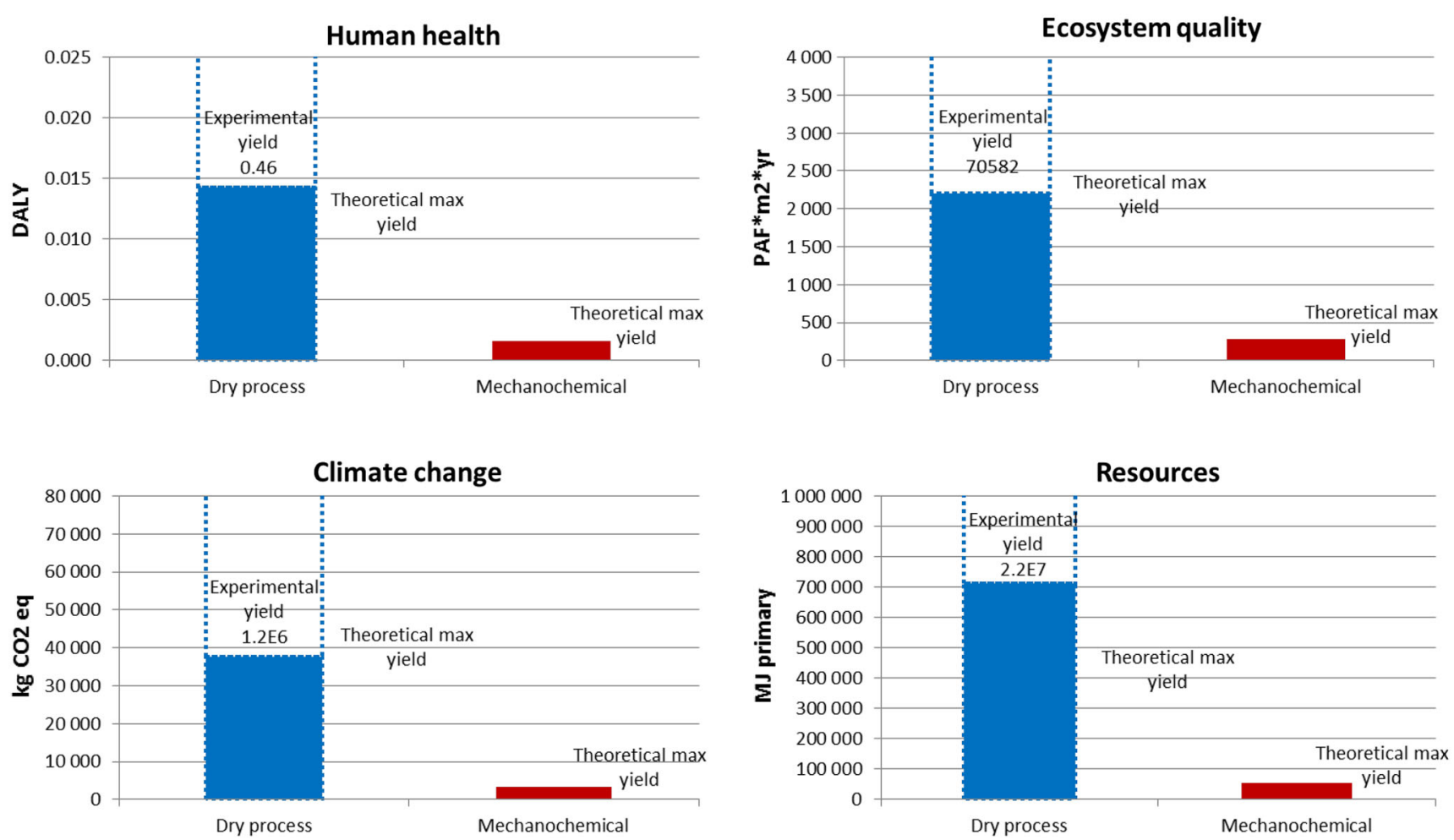

Fig. 6 LCI comparison of evaporation method and mechanochemical method for aluminum particles

Table 9 LCI for mechanochemical method of producing aluminum nanoparticles at $100 \%$ yield

\begin{tabular}{lllllll}
\hline & & Aluminum precursor & Reducing agent & Electricity for milling & Nitrogen & Washing agent \\
\hline Human health & DALY & 0.00001 & 0.00001 & 0.00006 & 0.00023 & 0.00126 \\
Ecosystem quality & PAF m $^{2}$ year & 3.3 & 2.1 & 3.9 & 42 & 228 \\
Climate change & $\mathrm{kg} \mathrm{CO}_{2}$ eq & 17 & 16 & 370 & 522 & 2470 \\
Resource depletion & $\mathrm{MJ} \mathrm{Primary}$ & 249 & 304 & 5969 & 8778 & 37,377 \\
\hline
\end{tabular}

Table 10 Average particle size according to process

\begin{tabular}{lll}
\hline & Arc process $(\mathrm{nm})$ & Chemical process $(\mathrm{nm})$ \\
\hline Copper & 58.0 & $1-175$ \\
Silver & 15.7 & Varying \\
Zinc & 146.9 & $50-100$ \\
Aluminum & 20 & 57 \\
\hline
\end{tabular}

were carried out by the University of Duisburg-Essen Germany (partner A) and partly at Metal Nanopowders Ltd., UK (partner B). As can be seen the LCI can be significantly reduced by optimizing the process closer to the parameters used by Metal Nanopowders Ltd. The experiments done at University of Duisburg-Essen were more stable and were able to run for longer durations but apparently at a lower production efficiency.
Table 11 LCI points for the arc process compared with chemical process based on country electricity mix (20\% production efficiency for arc process)

\begin{tabular}{llllll}
\hline \multirow{5}{*}{} & \multicolumn{4}{l}{ Arc process } \\
\cline { 2 - 6 } & EU-27 & Germany & Norway & Spain & USA \\
\hline Copper & 0.197 & 0.191 & 0.148 & 0.203 & 0.203 \\
Silver & 1.421 & 1.394 & 1.204 & 1.447 & 1.448 \\
Zinc & 0.164 & 0.161 & 0.137 & 0.167 & 0.167 \\
Aluminum & 716 & 682 & 434 & 749 & 751 \\
\hline
\end{tabular}

\section{Conclusions}

The LCA proved to be a useful tool for the evaluation of the different nanoparticle production processes. However, the intermediate and final yields and the power requirement for the processes are poorly described in the literature, and 
assumptions are made in order to compare the processes. The accuracy of the comparison could be improved with more accurate yield and energy demand data.

This study showed that the electric arc discharge evaporation and condensation technique for producing metallic nanoparticles has lower LCI, and so lower environmental impact, in most categories compared with the studied chemical synthesis routes, under the assumption that the yields for both of the routes are similar except for the production of aluminum particles. For aluminum the mechanochemical route is significantly more environmentally friendly and should be the preferred over the arc discharge process. Further improvement of the arc method is possible by the reuse of the exhaust gas as carrier gas.

Future work will also address nickel, gold and presumably also $\mathrm{FeCr}$ and $\mathrm{NiCu}$ alloy nanomaterials.

Acknowledgements This paper is an extension (with results on aluminum nanoparticles) of a paper presented at ECOS2014 in Turku, Finland, June 2014 (ecos2014.abo.fi). The authors want to acknowledge the support from the European Union's Seventh Framework program under grant agreement no. 280765 (BUONAPART-E) http:// www.buonapart-e.eu/ and Academy of Finland's Graduate School of Energy Efficiency and Systems (2012-2015) for the financial support for the research. The authors would also like to thank Lein Tange from ICL-IP Europe B. V. for his assistance in finding LCA data on the production of bromine gas and Dr. Mark Paskevicius of Institute for Kemi, Aarhus University, Denmark, for data on the mechanochemical process for aluminum nanoparticle production.

Open Access This article is distributed under the terms of the Creative Commons Attribution 4.0 International License (http:// creativecommons.org/licenses/by/4.0/), which permits unrestricted use, distribution, and reproduction in any medium, provided you give appropriate credit to the original author(s) and the source, provide a link to the Creative Commons license, and indicate if changes were made.

\section{References}

1. BUONAPART-E webpage: http://www.buonapart-e.eu/. Accessed 3 Jan 2014

2. Hontañón, E., Palomares, J.M., Stein, M., Guo, X., Engeln, R., Nirschl, H., Kruis, F.E.: The transition from spark to arc discharge and its implications with respect to nanoparticle production. J. Nanopart. Res. 2013, 15 (1957)

3. Stein, M., Kiesler, D., Kruis, F.E.: Adjustment and online determination of primary particle size in transferred arc synthesis of copper nanoparticles. Aerosol Sci. Technol. 47(11), 1276-1284 (2013)

4. Attainable particle size, production rate and energy efficiency for all materials. BUONAPART-E Deliverable No. D2.3. 31 July 2013

5. Buonapart-e project data received 22.05.2014 from Matthias Stein, Universität Duisburg-Essen, Nanostrukturtechnik, Duisburg, Germany (personal communication)

6. Lisiecki, I., Billoudet, F., Pileni, M.P.: Control of the shape and the size of copper metallic particles. J. Phys. Chem. 100, 4160-4166 (1996)

7. Wu, Y., Kelly, M.T., Ortega, J.V.: Synthesis of sodium borohydride for energy applications. Am. Chem. Soc. Div. Fuel Chem. 48(2), 939 (2003)

8. Lee, P.C., Meisel, D.: Adsorption and surface-enhanced raman of dyes on silver and gold sols. J. Phys. Chem. 86, 3391-3395 (1982)

9. Ghanta, S.R., Rao, M.H., Muralidharan, K.: Single-pot synthesis of zinc nanoparticles, borane (BH3) and closo-dodecaborate (B12H12)2 - using LiBH4 under mild conditions. Dalton Trans. 42, 8420 (2013)

10. Simonson, M., Blomqvist, P., Boldizar, A., Möller, K., Rosell, L., Tullin, C., Stripple, H., Sundqvist, J. O.: Fire-LCA model: TV case study. Swedish National Testing and Research Institute, SP Report 2000:13, p. 190

11. Paskevicius, M., Webb, J., Pitt, M.P., Blach, T.P., Hauback, B.C., Gray, E.M.A., Buckley, C.E.: Mechanochemical synthesis of aluminium nanoparticles and their deuterium sorption properties at 2 kbar. J. Alloys Comp. 481, 595-599 (2009) 